\title{
Transit Operator Evaluation of Three Wheelchair Securement Systems in a Large Accessible Transit Vehicle
}

Linda van Roosmalen, Douglas Hobson, Patricia Karg, Emily DeLeo, Erik Porach

University of Pittsburgh

\begin{abstract}
The safety, ease of use, and independent use of three wheelchair securement systems and three different types of wheeled mobility devices (WhMD), including a manual wheelchair, a powered wheelchair, and a three-wheeled scooter, were evaluated by eight vehicle operators of a large accessible public transit vehicle (LATV). The securement systems included a forward-facing four-point tiedown system, a prototype forward-facing autodocking system, and a prototype rear-facing-wheelchair passenger (RF-WP) system. The eight LATV operators transported wheelchair-seated passengers in each wheelchair securement system, after which they completed a questionnaire.

Operators responded generally positively to the autodocking and RF-WP systems because they were observed by the drivers to be quicker and easier to use and allowed more independent use by wheelchair-seated passengers compared to the four-point tiedown system. From all three securement systems, operators favored the forward-facing autodocking system, because no assistance from operators is required to use it and most users preferred the forward-facing orientation in the vehicle. The autodocking system was perceived to be safe and easy to use by wheelchair-and scooter-seated passengers. These study results promote the need for alternative and improved securement systems that can be used by wheelchair and scooter-seated
\end{abstract}


passengers that travel in LATVs in forward- or rearward-facing directions. Ideally, future securement solutions should not require assistance from LATV operators for their operation and should allow wheelchair- and scooter-seated passengers to ride public transportation safely and independently.

\section{Introduction}

In the United States, the majority of public transportation vehicles have become accessible to individuals using wheeled mobility devices (WhMD). This is largely due to the U. S. Department of Transportation's (DOT) Americans with Disabilities Act (ADA) regulations requiring public transportation to be fully accessible to individuals with disabilities (U. S. DOT 2010). Lifts and ramps provide an independent means to board and exit motor vehicles, and wheelchair securement stations equipped with wheelchair tiedown and occupant restraint systems (WTORS) are commonly installed so that operators can safely secure wheelchairs and restrain wheelchair-seated passengers. However, section 37.5 of DOT's ADA stipulates that vehicle operators cannot require the use of occupant restraints by wheelchair passengers unless transit authorities have adopted a written policy that mandates the use of occupant restraints (U. S. DOT 2010).

\section{Current Status of on WTORS used on LATVs}

In general, WTORS in large, accessible transit vehicles (LATV) cannot be independently used by wheelchair users and require assistance from a vehicle operator. Several studies have investigated the use and, more importantly, the non-use of WTORS by operators when they transport wheelchair-seated individuals in LATVs (Abelson et al. 2008; Foreman and Hardin 2001). The Foreman and Hardin (2001) survey focused on challenges faced by operators in LATVs related to WTORS. They found that scooters, in particular, are difficult to secure and often cannot be adequately secured due to a lack of identifiable securement points and limitations of currently-installed wheelchair securement technologies that require narrow frame members for looping around webbing-type straps and hardware. In fact, 46 percent of survey respondents reported that operators encounter difficulties when attempting to secure three- and four-wheel scooters (Foreman and Hardin 2001). Current WTORS also require operators to leave their driver station and to come in close contact with passengers (Foreman and Hardin 2001). Tiedown systems using retractor technology are easy to tighten; however, tiedowns with the traditional manual adjustment buckles are time-consuming to use (Blower et al. 2005). Boarding a wheelchair in combination with a lengthy securement process 
conflicts with the daily struggle for vehicle operators to meet bus route schedules. Finally, wheelchair-seated passengers and operators complain about dirty, twisted, or missing tiedown straps and occupant restraints (Abelson et al. 2008).

ADA defines a wheelchair as a mobility aid belonging to any class of three- or fourwheeled devices, usable indoors, designed for and used by individuals with mobility impairments, whether operated manually or powered. A common wheelchair does not exceed 30 inches in width and 48 inches in length measured two inches above the ground and does not weigh more than 600 pounds when occupied (U.S. DOT 2010). Non-common wheelchairs that do not fit the definition of a common wheelchair can make the securement process difficult and sometimes even impossible (Foreman and Hardin 2001; Hardin et al. 2002; Project Action 2008). An additional complication is that long and narrow WhMDs such as scooters have a high center of gravity in combination with a narrow wheelbase and may therefore tip over when not properly secured. A study done by Turkovich et al. (2011) demonstrated that common scooters and wheelchairs tip over during normal vehicle maneuvers (such as turning and braking) in an LATV. It is not uncommon in other countries for transit systems to prohibit the transport of over-size mobility devices and scooters on LATVs (United Kingdom Department for Transport 2006). In the U.S., however, ADA regulations prohibit discrimination and require transit authorities to accommodate any individual seated in a common wheelchair. More and more WhMDs are being produced that comply with the RESNA WC19 voluntary industry safety standard for wheelchairs used as seats in motor vehicles. Compliance with the standard improves safety and the ease of application of four-point strap-type tiedowns by requiring four easily-identifiable securement points on the wheelchair (ANSI/RESNA 2001). These WC19 wheelchairs are crash-tested, and their four securement points are clearly labeled and attached or integrated into the wheelchair or seating frame. WC19 wheelchairs also have anchorage points for a pelvic restraint that has been designed to protect wheelchair-seated occupants riding in a motor vehicle and are rated for accommodation of vehicle-anchored occupant restraints. The use of WC19 wheelchairs, however, is limited at this point in time, and challenges with securement use remain an issue.

There are additional issues with the current vehicle-installed WTORS that affect how LATV operators adhere to safe and best practices. Some wheelchair-seated passengers refuse to have their wheelchair secured to the vehicle. Dealing with unwilling passengers makes operator adherence to company policy and following best practices, i.e., securing wheelchairs and restraining occupants, difficult. 
Inconsistent policies and inconsistent reinforcement of policies may result either in trip denial for wheelchair passengers unwilling to be secured or wheelchair passengers traveling unsafely. Insufficient operator training in combination with non-common wheelchairs onboard LATVs can also result in poor wheelchair securement practices and an increased injury risk to wheelchair-seated and ambulatory passengers (Foreman and Hardin 2001). An additional concern is the current confusion and lack of knowledge that exists among LATV operators as to whether or not wheelchair passengers must wear a seatbelt and/or have their wheelchair secured, especially since other ambulatory passengers often do not require safety measures such as seatbelts on board LATVs (Foreman and Hardin 2001; Hardin et al. 2002). Although the use of WTORS may minimize risk to WhMD passengers and others on board LATVs, 16 percent of respondents in an operator study done by Foreman and Hardin (2001) reported injuries that did not occur to wheelchair users but to operators as a result of using WTORS on WhMDs. These occupational injuries included back strains, arm and shoulder injuries, carpel tunnel syndrome, cuts, scrapes and bruises. Improved WTORS are being developed to address some of these issues.

\section{Improvements to WTORS}

Oregon State University was one of the first to develop an operator-independent securement solution for wheelchair passengers that requires a wheelchairmounted bracket (adaptor) that engages with a vehicle-mounted docking device (Hobson and van Roosmalen 2007). The concept of autodocking was further explored at the University of Pittsburgh (Hobson and van Roosmalen 2007). This concept was based on a standardized universal interface geometry that is specified in ISO 10542 and RESNA WC19 standards (ISO 2005). Autodocking technologies have yet to become commercially available and successful. Success depends greatly on the mutual efforts of wheelchair manufacturers (to produce wheelchairs with universal [ISO] adaptors) and transit organizations (to install ISO-compliant docking devices in LATVs).

Another passive securement solution has been adopted in European public transit and some U.S. and Canadian public transit systems (Hunter-Zaworski 2004). This technology can be identified by its rear-facing approach to containing occupied WhMDs in LATVs (RF-WP systems). This system, in its simplest form, consists of a padded area behind a (rear-facing) wheelchair user and usually includes an aisle-mounted structure to prevent tipping or swerving of WhMDs. This system is believed to be operator- and wheelchair-passenger friendly in that it allows inde- 
pendent operation by most WhMD passengers that board LATVs. A concern with currently used RF-WP systems is the insufficient lateral containment this system offers to WhMDs that are exposed to accelerations related to LATV turning.

Research remains ongoing to understand the safety of the various securement systems during normal and emergency driving maneuvers in LATVs (Turkovich et al. 2011; van Roosmalen et al. 2011). Shaw (2008) found that public transportation is a very safe mode of transportation and accidents due to vehicle crashes are rare. However, incidents related to normal vehicle maneuvering are more frequent and have been reported by several researchers in the field (Frost and Bertocci 2009, 2010; Songer et al. 2004). Incidents in LATVs are commonly due to poor wheelchair securement and/or restraint of wheelchair- and scooter-seated passengers (Frost and Bertocci 2009).

This study's long-term goal is to minimize wheelchair-related incidents and lower risk of injury among WhMD-seated passengers traveling on LATVs by providing guidance on securement and restraint design approaches that will increase use. It also aims to listen to the voice of the customer (operators, passengers) when selecting technologies for the fast pace environment of modern public transportation. This study is part of a broader study where wheelchair- and scooter-seated individuals were surveyed and asked for their perceived safety, comfort, and independence when using three types of wheelchair securement stations on board an LATV (Turkovich et al. 2009; van Roosmalen et al. 2011). The results in this publication are focused on operators of LATVs and their perceived ease of use of three types of wheelchair securement stations. Findings from this study clarify the preferred operator and wheelchair user responsibilities with respect to WTORS and guides product designers in the improvement of existing and development of alternative wheelchair safety systems on board LATVs that meet operator needs and wheelchair-seated passenger needs.

\section{Objective}

The perceived safety and usability of prototype autodocking and RF-WP systems was compared to a commercial four-point tiedown system by means of a survey. The objective was to learn LATV operators' and operator trainers' opinions on ways in which wheelchair securement systems can be improved to optimize system safety, usability, and operational feasibility in the LATV environment. 


\section{Test Method}

Institutional Review Board (IRB) approval for this study was obtained from the University of Pittsburgh IRB (\#PRO08010172). The investigators collaborated closely with the Port Authority of Allegheny County, who assisted with the selection of LATV operators who participated in the study.

\section{Test Wheelchairs}

Two commonly-used wheelchairs and one scooter (hereafter referred to collectively as "wheelchairs") were used in the study. An effort was made to select wheelchairs that complied with voluntary standards RESNA WC19 or ISO 7176-19 and could be easily adapted to work with the wheelchair securement systems to be evaluated (ISO 2001; ANSI/RESNA 2001). To be compatible with the test systems and setup, each wheelchair required at least four tiedown securement points, an autodocking adaptor meeting specifications of ISO 10542-3 for a Universal Design Interface Geometry (UDIG) (International Standards Organization 2005), and a wheelchair-anchored pelvic restraint (ANSI/RESNA 2001). Wheelchairs that comply with RESNA WC19 and ISO 7176-19 provide four easily-accessible securement points on the frame for the attachment of tiedown straps. Additionally, RESNA WC19-compliant wheelchairs are equipped with anchors for a crash-tested pelvic restraint (ANSI/RESNA 2001). The three devices selected for the study included:

1. An Invacare TDX-SP power wheelchair (Invacare, Cleveland, $\mathrm{OH}$ ), fully compliant with RESNA WC19 and equipped with four tiedown securement points and a frame-mounted pelvic belt. With assistance from Invacare, a prototype UDIG adaptor was designed, fabricated, and installed onto the TDX-SP (Figure 1).

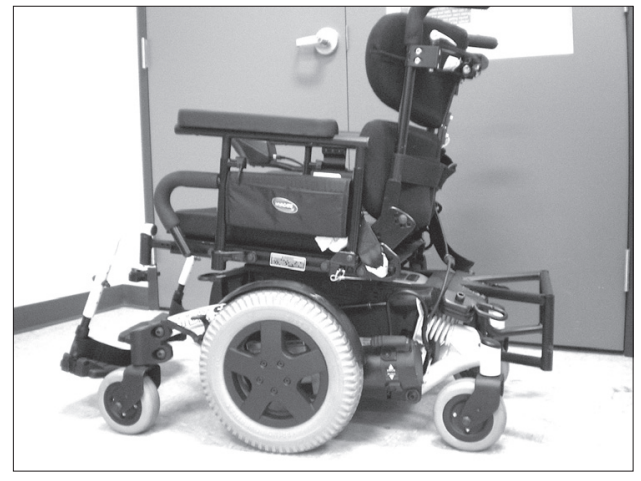

Figure 1. Invacare TDX-SP power wheelchair, equipped with four tiedown securement points, UDIG adaptor, and frame-mounted pelvic restraint 
2. A Quickie 2 manual wheelchair (Sunrise Medical, Longmont, CO), ISO 7176-19-compliant and equipped with four tiedown securement points, was modified with the help of Sunrise Medical to add a prototype UDIG adaptor to the wheelchair. A wheelchair-anchored pelvic restraint was also added to the Quickie 2 (Figure 2).

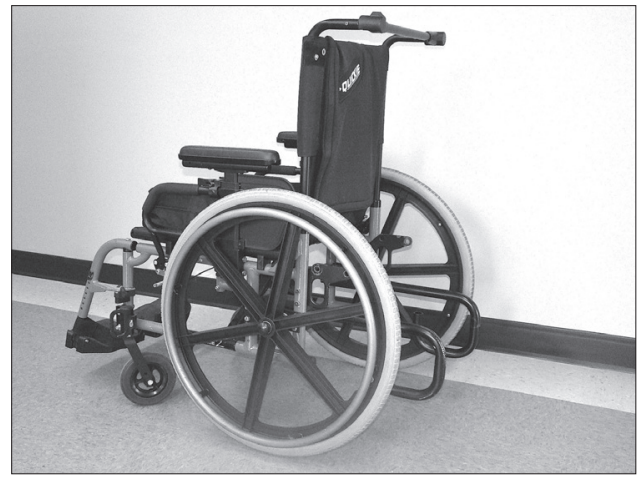

Figure 2. Quickie 2 manual wheelchair, equipped with four tiedown securement points, UDIG adaptor, and frame-mounted pelvic restraint

3. An Amigo-RD three-wheel electric scooter (Amigo Mobility International, Bridgeport, MI) was modified with help from Amigo Mobility International. The scooter was equipped with two front aluminum tiedown securement points, a prototype UDIG adaptor with two integrated rear tiedown securement points, and a UDIG-anchored pelvic restraint (Figure 3).

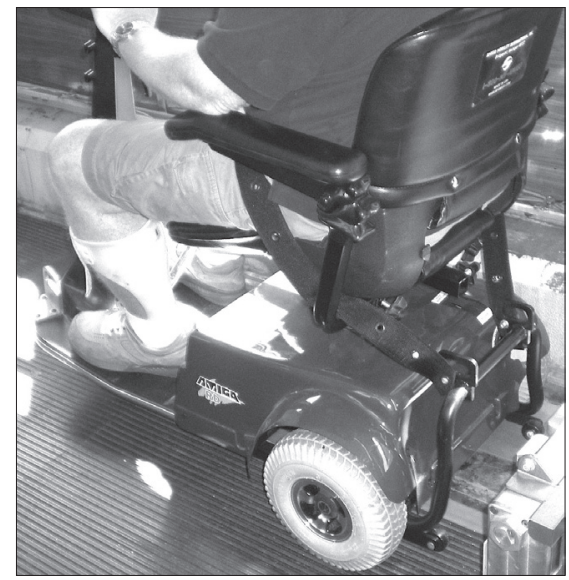

Figure 3. Amigo-RD scooter, equipped with four tiedown securement points, UDIG adaptor, and UDIG-mounted pelvic restraint 
Pelvic restraints were prototypes provided by BodyPoint (BodyPoint, Seattle, WA) and Q'Straint (Q'Straint, Fort Lauderdale, FL). None of the modified components (UDIG adaptors or wheelchair-anchored pelvic restraints) were strength-tested prior to the in-vehicle testing. However, materials and anchor points of sufficient strength to withstand low-g loading were selected, and best engineering practices used.

\section{Wheelchair Securement Systems}

Three types of wheelchair securement systems were used in the study:

1. A four-point strap-type tiedown system (QRT Deluxe Retractable System, Q'Straint, Fort Lauderdale, FL) (Society of Automotive Engineers 1999) (Figure 4).
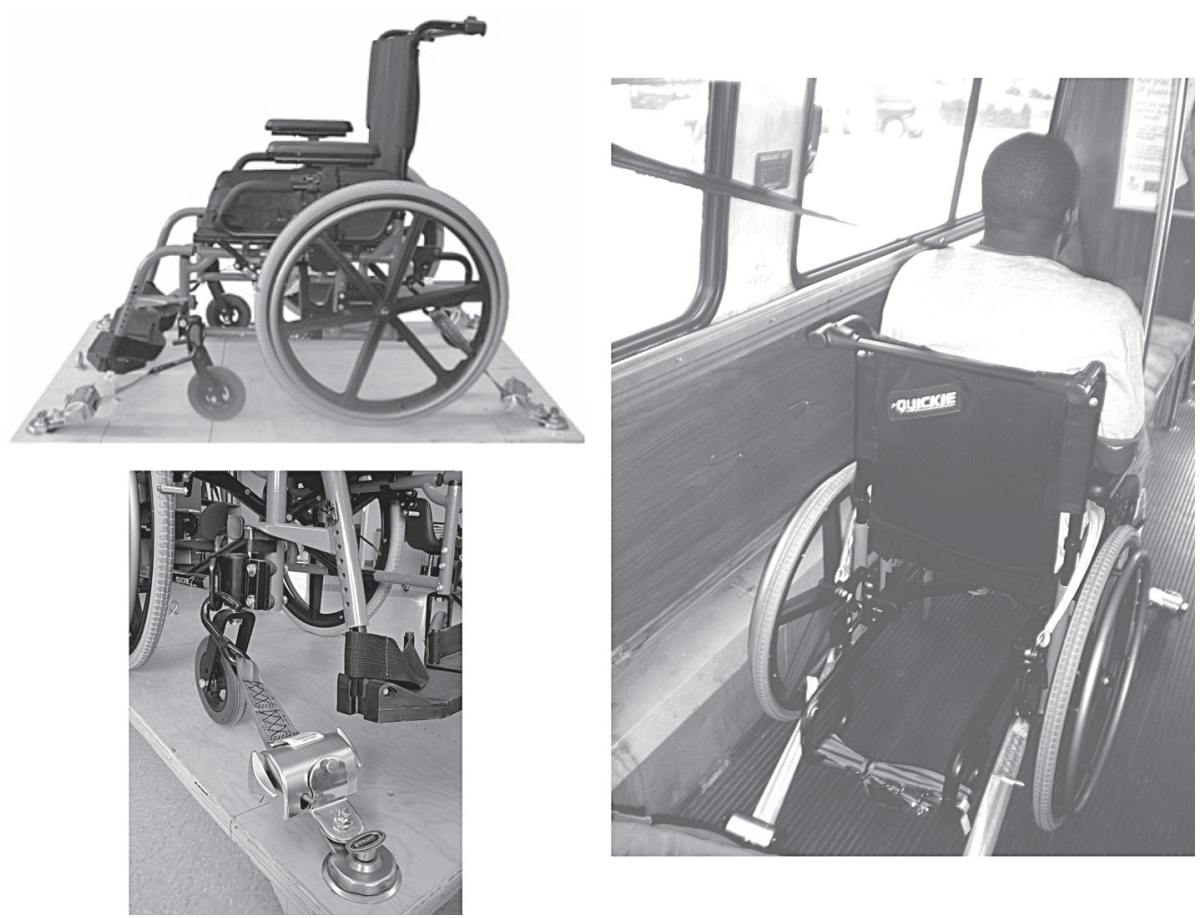

\section{Figure 4. Manual wheelchair secured with self-retracting four-point strap-type tiedown system (Q'Straint, Fort Lauderdale, FL)}

2. A prototype forward facing autodocking system developed by the University of Pittsburgh and Sure-Lok (Sure-Lok, Bethlehem, PA) in compliance with ISO 10542-3 (ISO 2001, 2005). The system consisted of a pneumatically-powered 
mechanism that automatically engaged with the UDIG adaptor on the rear frame of a wheelchair (Figure 5). To release the wheelchair from the autodocking system, a wall-mounted switch was activated by the wheelchair user.

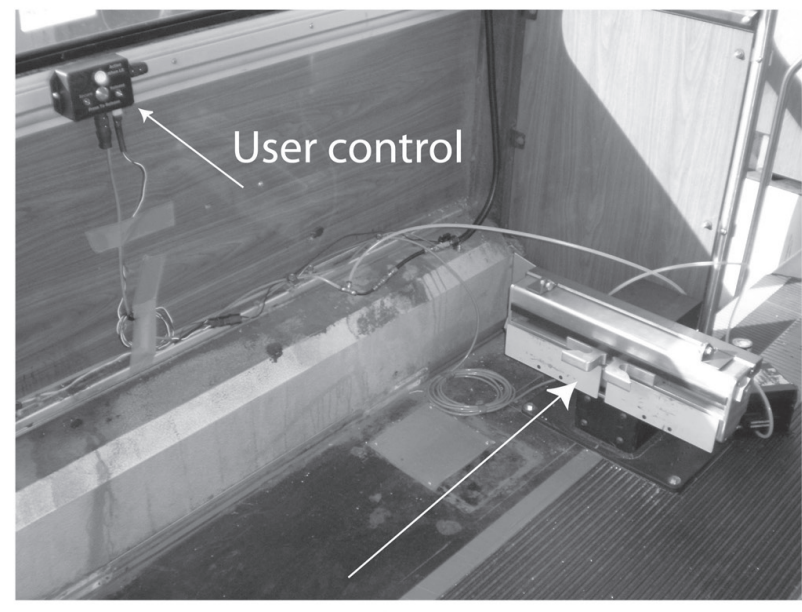

Auto-docking system

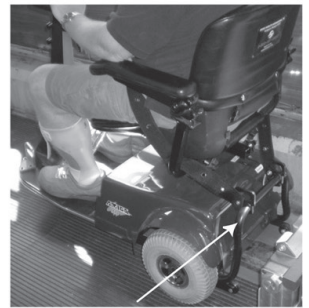

UDIG adaptor

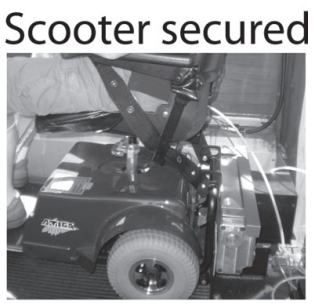

\section{Figure 5. Autodocking system installed in LATV and scooter equipped with UDIG adaptor backing up and secured by autodocking system}

3. A prototype rear-facing wheelchair passenger (RF-WP) system developed by the University of Pittsburgh and Q'Straint (Fort Lauderdale, FL) in compliance with draft standard ISO 10865-1 (ISO 2010). This system had a rear-facing head and backrest and a wall-side contact plate. A wheelchair user faces towards the rear of the vehicle while backed up into the system's head and backrest. The wheelchair does not require frame-mounted hardware and is held in place by two pneumatically-engaged aisle-side and window-side plates. To exit the system, wheelchair users activated a wall-mounted switch disengaging the aisle-and window-side plates. 


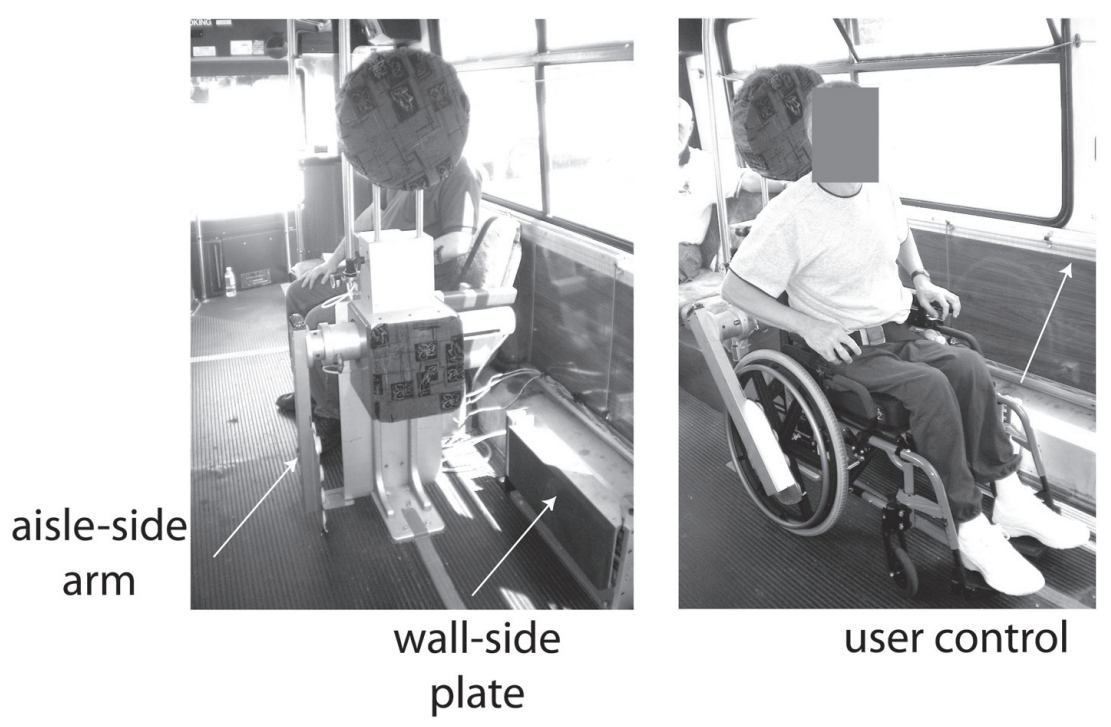

Figure 6. a) Rear-facing wheelchair passenger (RF-WP) system with aisle-side arm and wall-side contact plate, and $b$ ) example of manual wheelchair positioned in RF-WP system

\section{In-Vehicle Test Setup and Driving Course}

A 40-foot Orion V high-floor LATV (Orion Bus industries, Inc., Oriskany, NY) was provided by the Port Authority of Allegheny County. The four-point tiedown system was installed behind the driver (Figure 4). The prototype autodocking and RF-WP systems were placed on the non-driver side of the vehicle (Figures 5 and 6). Testing took place in the Oakland area in Pittsburgh on an urban course representing typical driving conditions (Figure 7).

Each vehicle operator was scheduled to drive the vehicle with a manual wheelchair user, a power wheelchair user, and a scooter user. Trips were repeated on a preplanned urban route to allow the operator to experience each wheelchair secured in each of three securement systems. Prior to the trials, each wheelchair securement station was briefly introduced to the operators. The operators observed and aided as needed as the passengers entered and exited the vehicle, each wheelchair was secured, and passenger belt restraints were positioned. For safety, the use of a wheelchair-mounted pelvic restraint was mandatory during the driving test. The operators were instructed that the use of the vehicle-mounted upper torso restraint was optional and, therefore, provided only upon request by the wheelchair-seated passenger. 


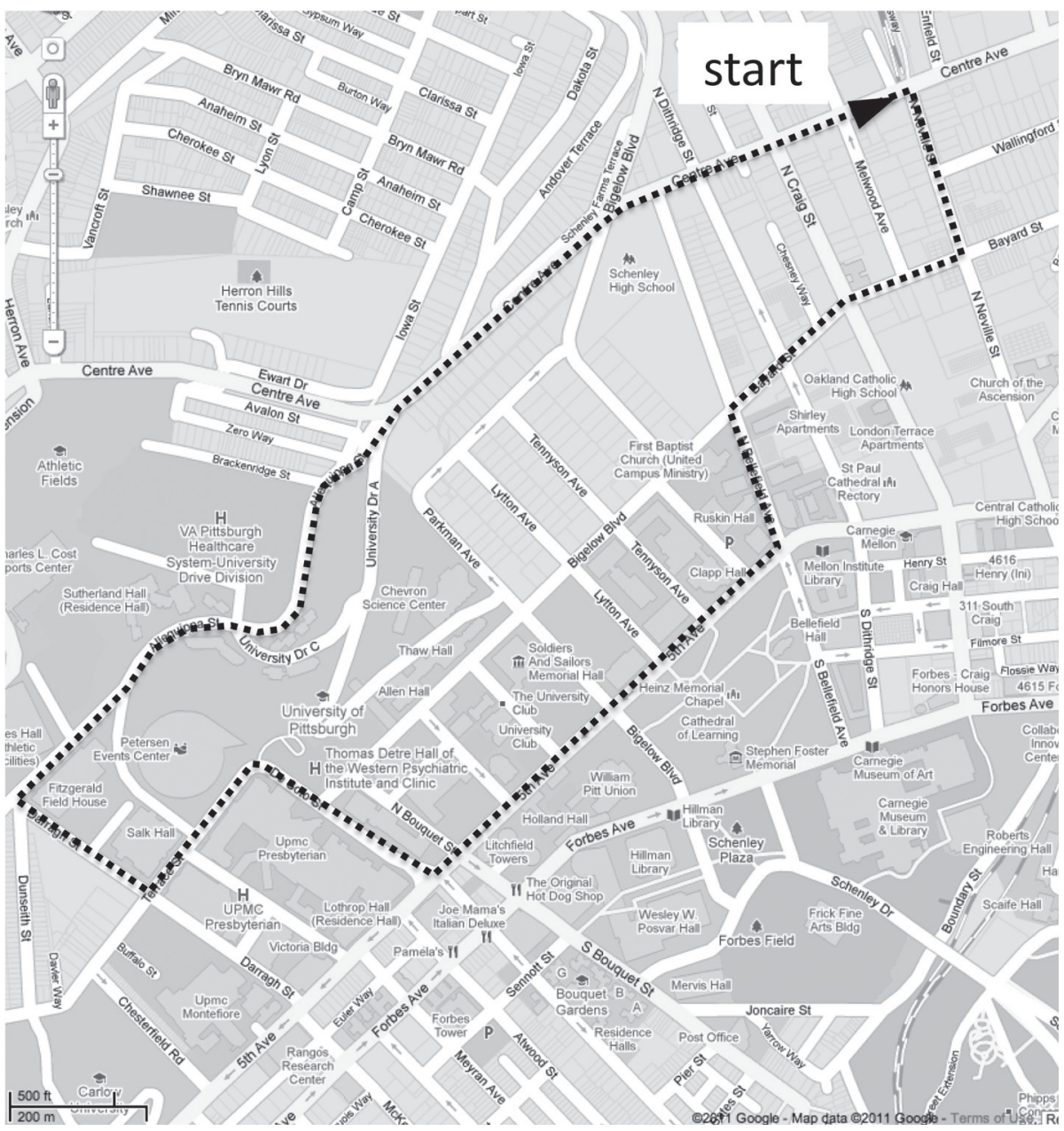

Figure 7. Map illustrating vehicle test route in Oakland

A questionnaire was developed and administered prior to and after completion of the in-vehicle trials. The pre-test part of the survey covered questions on demographics and operator experience with existing wheelchair securement and occupant restraint systems. The post-test part of the survey asked for ratings on the ease of use, perceived safety, and independent use of the three different wheelchair securement systems. Operators were also asked to identify what they liked and disliked about each securement syste, which system they liked the best and least, and which was most and least safe for the passenger, was easiest and hardest to use, would be the most and least comfortable for the passenger, took the most and 
least time to use, and would allow the most and least independent use. Operators were also asked about their favorite securement system and to suggest system improvements. Findings from the survey were reported qualitatively.

\section{Pre-Test Results}

All study participants were instructors (trainers) and operators of the Port Authority of Allegheny County. Five participants were male and two participants were female. Six participants had been involved with public transportation operations for over 10 years in the role of vehicle operator and instructor. One participant had worked as an instructor for less than five years. Four of the participants were between ages 40 and 50 years and three were over 50 . All operators were familiar with the use of a four-point strap-type tiedown system, and all stated that they typically ask wheelchair-seated passengers if they require assistance with wheelchair securement. Five operators said wheelchair users sometimes requested their wheelchair to be secured, one was frequently asked, and one was rarely asked. The frequency of use of wheelchair securement systems ranged from a few times per week to less than once per year.

All operators reported having had issues with passengers not wishing to use wheelchair securement systems. Five operators responded that wheelchair securement systems they use are dirty. Three operators mentioned other problems such as interference of securement systems with wheelchair components, the securement system being time-consuming, and the system application requiring uncomfortable personal contact with passengers. Two operators said the securement system was difficult to use, and one participant stated that, occasionally, the securement system would not function properly. According to four operators, the securement of scooters posed the most problems, and one participant reported that securing power wheelchairs was most difficult.

All operators were trained in the use of a wheelchair occupant restraint (seatbelt) system, and all typically offer assistance to passengers in the use of seatbelts. Five participants said that passengers only sometimes ask to use the seatbelt, one was rarely asked, and one was never asked. Issues encountered with wheelchair occupant restraints include lack of belt cleanliness (mentioned by five participants). Four participants said that passengers do not wish to use seat belts, and three participants mentioned discomfort with personal contact as issues related to seat belt use. Two participants indicated issues regarding restraint interference with wheelchair components and restraints being too time-consuming to use. 
Operators were asked if they ever felt uncomfortable or that it was unsafe for wheelchair-seated passengers during transit; four participants indicated rarely or never, and three participants said they occasionally felt this way. Participants felt uncomfortable when wheelchair-seated passengers refused to be secured or restrained or when they were unable to be secured or restrained properly due to mechanical issues with the wheelchair or WTORS. One operator mentioned being worried about other standing passengers falling onto or against a wheelchairseated passenger.

When it comes to using the wheelchair ramp or lift when loading/unloading passengers, four operators said they rarely or never felt uncomfortable or that is was unsafe. Three operators said they would sometimes feel uncomfortable or unsafe and listed ramp fatigue (due to frequent ramp use), ramp malfunction, and the risk of the wheelchair-seated patrons tipping over on the ramp or lift as reasons.

When asked the level of assistance they typically provide to wheelchair-seated passengers, five operators said they provided assistance with securing wheelchairs. Only one operator stated helping wheelchair-seated passengers with all five tasks listed (on/off ramp/lift, maneuvering into wheelchair station, securing the wheelchair, applying seat belts, and transferring in/out of the wheelchair).

The main dislike operators reported was the unsanitary four-point tiedown station due to accumulating dirt on straps and belts. Operators suggested that a wheelchair securement system that does not use straps can be more easily maintained and is more operator-friendly.

\section{Post-Test Results}

\section{Likes}

Operators were exposed to each wheelchair securement system while transporting individuals seated in a manual wheelchair, power wheelchair, or a scooter. Afterwards, operators were asked to describe the securement system characteristics they liked.

For the four-point tiedown system, two operators answered they did not like anything about the system. Other operators listed that they thought it was easy to use/ quick ( 3 operators) and they liked the idea of the retractable straps ( 2 operators) compared to tiedown systems with manually adjustable straps. For the autodocking system, five operators responded they liked that the system was user independent, and four commented positively on the system's ease of use/quickness. Inde- 
pendent use by wheelchair users of the rear-facing system was mentioned by five operators, as was security ( 2 operators) and ease of use/quick ( 3 operators). Worth pointing out is that operators found the four-point and the autodocking systems less space-consuming (2 operators). One operator listed the headrest on the RF-WP system as a likeable feature.

\section{Dislikes}

Operators were then asked to describe the dislikes of each system. The fourpoint tiedown system received the most dislikes ( 13 comments), the autodocking received fewer dislikes ( 7 comments), and the RF-WP system received the least amount of negative comments ( 5 comments).

Operators said they disliked the four-point tiedown system the most because it was difficult to use and time-consuming ( 4 comments) or dirty ( 3 comments) and because they felt they were invading the passengers' personal space ( 2 comments), it was operator dependent, and passengers opted to not use the system (2 comments). One operator also disliked that pieces of the system go missing. The possibility of system failure was listed as a concern in both the autodocking system (3 comments) and the RF-WP system (2 comments). Two operators also had concerns that the autodocking system may be difficult to use due to the need to back up and keep aligned with the system and the need for attachments (anchorages) on the wheelchair to allow it to work with the autodocking system. For the autodocking system, two operators said they liked everything about it, and one said they liked everything about the RF-WP system.

\section{Rating of Features}

Operators were asked to rate each securement system (on a scale from 1-10, with $1=$ Very Poor, $10=$ Excellent) on perceived safety, quick use, ease of use, and independent use by the wheelchair rider (see Figure 8). The RF-WP system received the best average score for safety/movement during stops and safety/movement during turns ( 9.9 and 9.6, respectively). The autodocking system had the highest average for wheelchair safety/movement during vehicle accelerations (9.6). On the rankings for quick use, the RF-WP system and autodocking received similar average ratings (8.7 and 8.6. respectively), with the four-point tiedown system receiving the lowest average rating (5.0). When operators were asked which system provided the best user independence, the RF-WP system received the highest average rating (9.4), with the four-point tiedown system falling far behind (0.6). Last, subjects were asked which system was easiest to use; the autodocking and RF-WP system 
received the same average rating (9.1), and the four-point tiedown system received the lowest average rating (2.7).

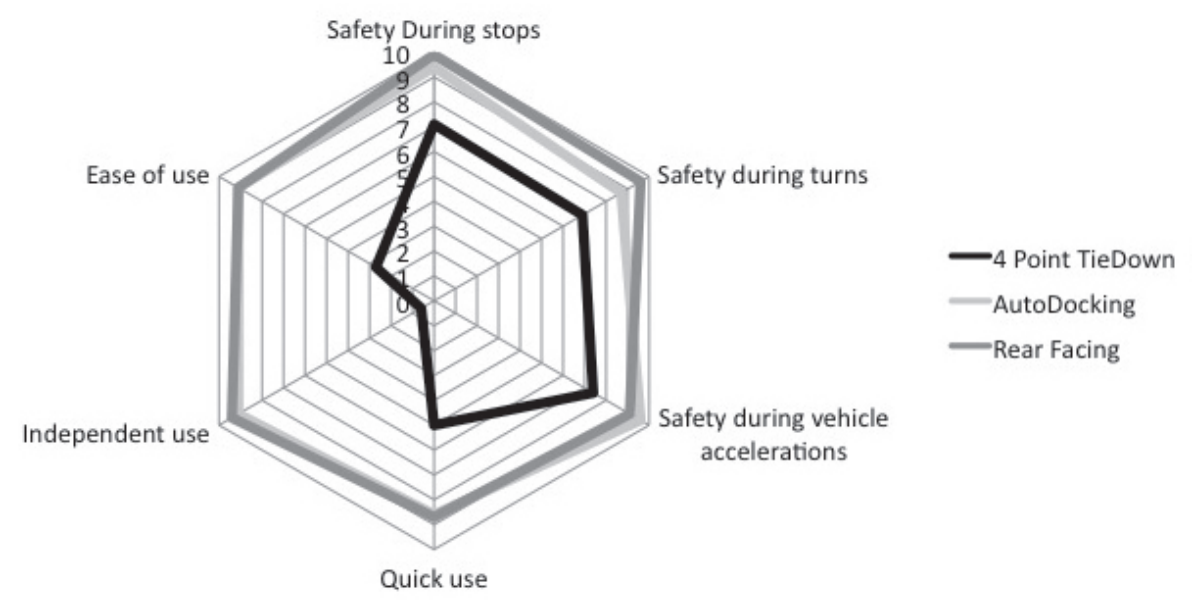

\section{Figure 8. Operator rating of likable features for each securement system}

\section{Most and Least Favorite}

After all systems were seen in operation, each operator was asked which station they liked best and least (see Figures 9 and 10). Three operators selected the autodocking system, three selected the RF-WP system, and one selected the fourpoint tiedown as his/her favorite system. When asked which station they liked the least, six operators chose the four-point tiedown system and one chose the RF-WP system. Four operators chose the RF-WP system as the most safe during braking and turning, and two chose the autodocking system as the safest. One operator did not have an opinion. The four-point tiedown system received all seven votes for the system being the least safe. The RF-WP system was voted the easiest to use, receiving six votes, and the autodocking system received one vote for the system that was easiest to use. The most difficult to use system was the four-point tiedown system (6 votes); the RF-WP system received one vote. The RF-WP system received five votes for securing the wheelchair the best, and the autodocking system received two votes. The four-point tiedown received five votes for securing the wheelchair the least; the autodocking system and RF-WP system received one vote each. The most time-consuming system was voted the four-point tiedown with six votes (1 subject failed to properly answer the question). The quickest station was voted the RF-WP system with six votes, and the four-point tiedown also received one vote for being the quickest. The RF-WP system received five votes for allowing passengers 
to be the most independent, and the autodocking system received two votes. The system chosen as allowing the least independent was the four-point tiedown, receiving all seven votes.

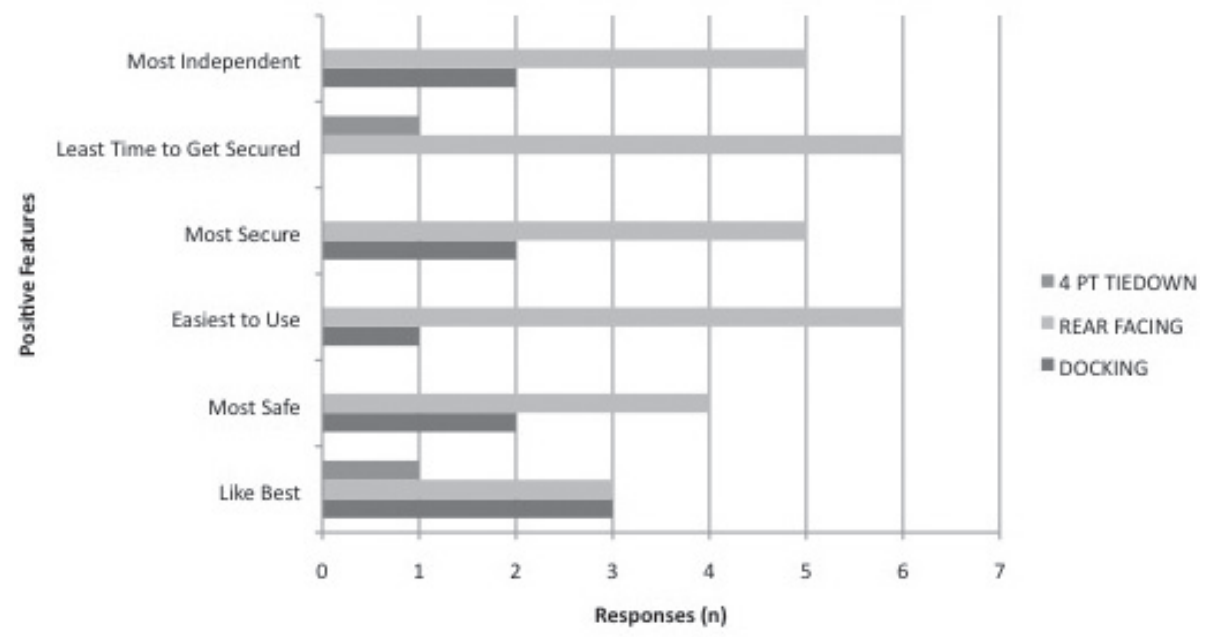

\section{Figure 9. Features liked most about each securement station}

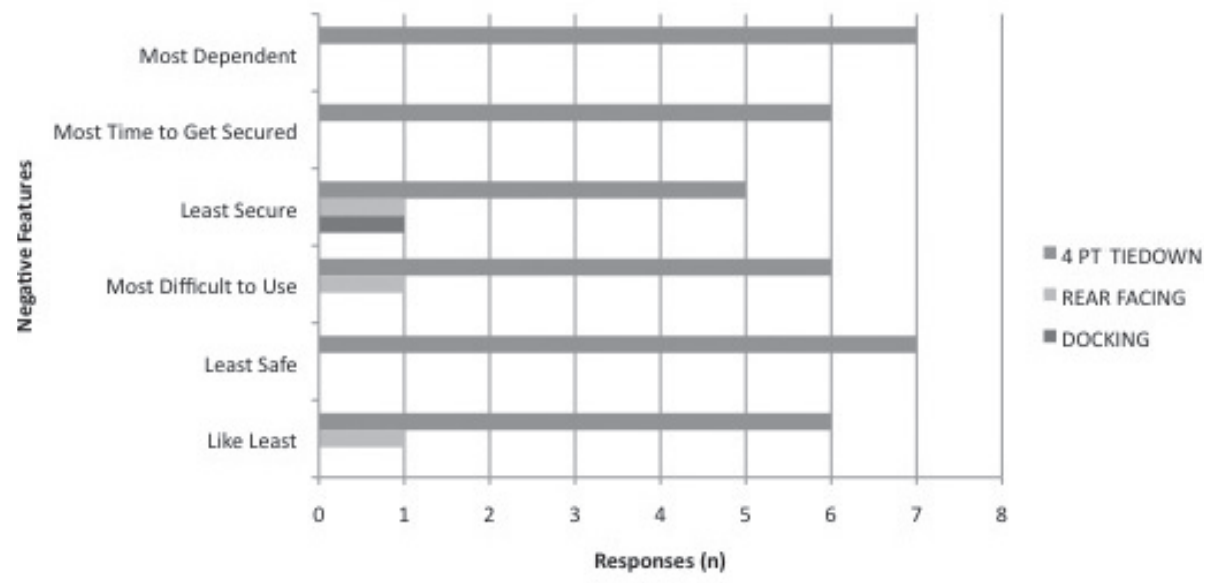

Figure 10. Features liked least about each securement station

\section{General Comments}

Operators were asked how use of their favorite systems would impact driving habits, assisting passengers, and training needs. Only two operators stated that use of their favorite system would alter their driving habits. These two operators 
reported the RF-WP system as their favorite system and noted that they would feel more comfortable about taking turns and stops because their passengers would be more secure. Five operators said that use of either the autodocking or rear facing system would alter how they assist passengers. Operators stated that they would have less of a role in the securement process and could see the safety system being used more often because it did not require as much assistance. Three operators felt use of the autodocking or RF-WP system would simplify the training needed for using securement systems. Two operators said that use of either of the prototypes would not change training, as training on all systems is still needed, especially if mechanical failure occurs. One operator said that the training would become more operator-friendly and that operators would accept the systems and the system training.

When asked what additional features they would like to see on any of the three systems, three operators commented that it would be useful if the securement systems had a warning device to alert the vehicle operator when the wheelchair or scooter was not secured properly. One subject noted that a handrail could be a useful addition to the four-point tiedown system.

In general, the surveyed operators seem to believe these securement systems are accessible to most wheeled mobility devices. Two operators are concerned that the autodocking system requires extra equipment to be placed on the wheelchair before it can be used in public transit systems. One operator commented that the RF-WP system works for scooters, which he believes are the toughest to secure with the existing securement technologies. Operators also mentioned they prefer securement systems that are simple to use and have no removable parts that can become detached, lost, or dirty. As a final comment, operators indicated that wheelchair securement systems should conserve space in LATVs.

\section{Discussion and Conclusions}

This unique study evaluated and compared the usability of three types of wheelchair securement systems by wheelchair-seated individuals on-board an LATV. Survey results were reported qualitatively on expert vehicle operators' and operator trainers' perceptions of usability, safety, and independent use of two prototype wheelchair securement stations and one state-of-the-art four-point tiedown system. An evaluation of the same three systems by 20 wheelchair and scooter users was also performed and previously published (Figures 11 and 12) (van Roosmalen et al. 2011). 


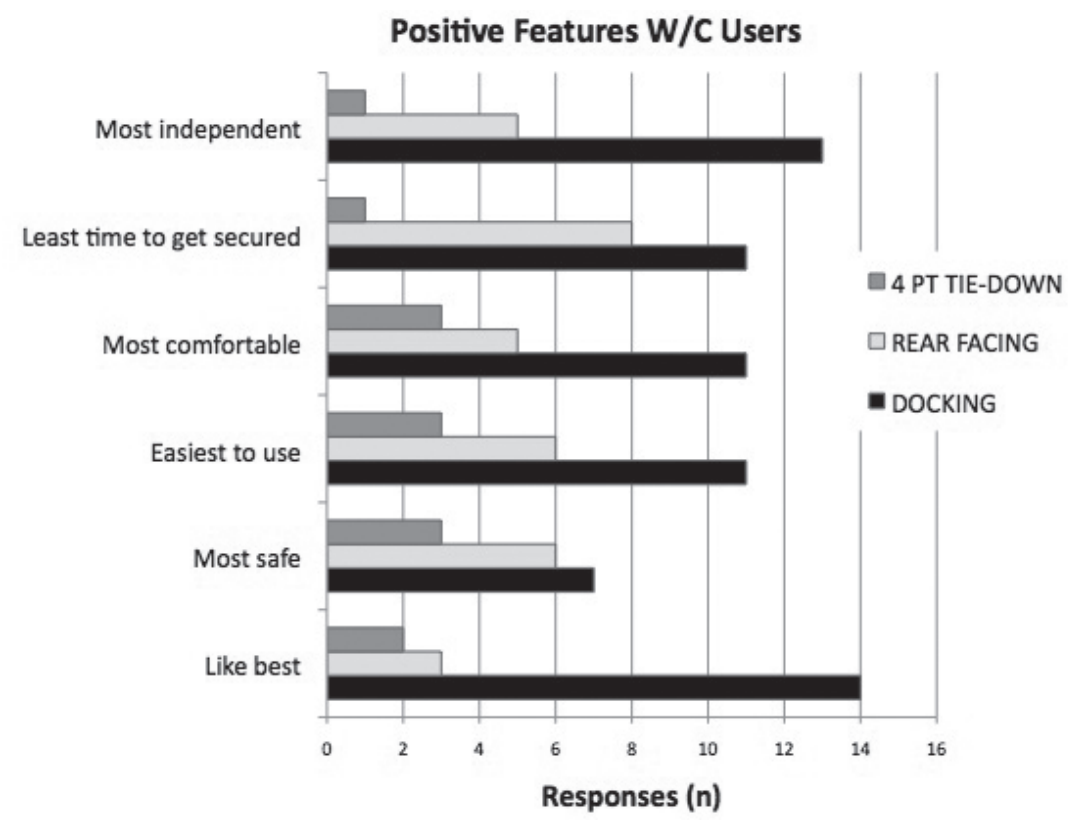

Figure 11. Number of wheelchair passengers choosing each securement system for positive features listed

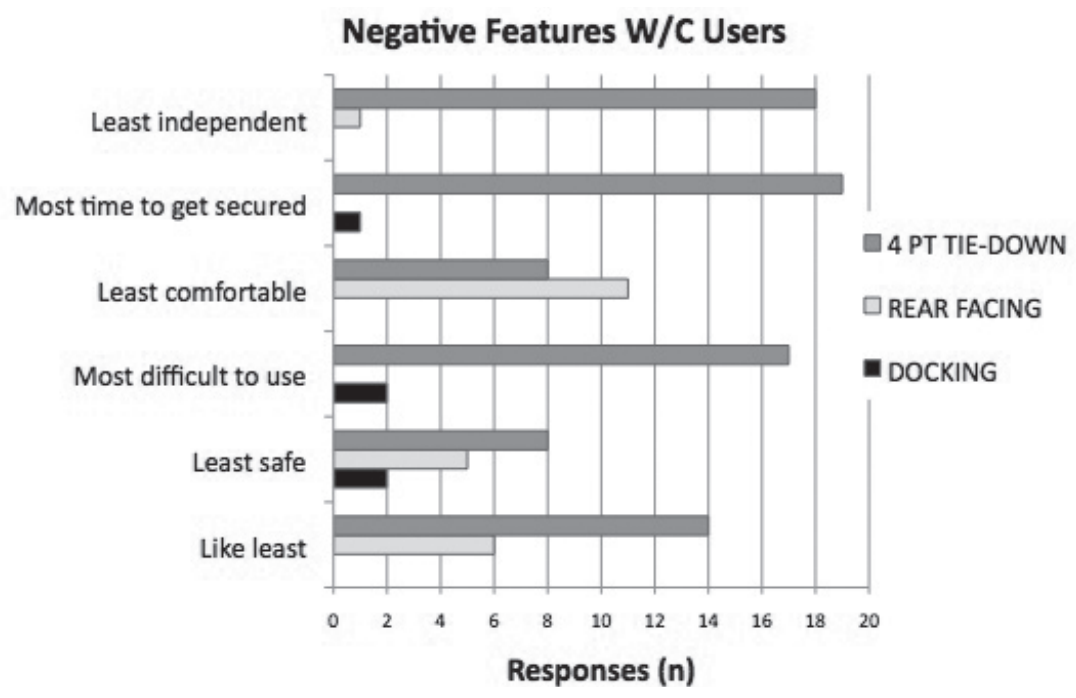

Figure 12. Number of wheelchair passengers choosing each securement system for negative features listed 
Operators liked the RF-WP system best due to the fact that it does not require operator assistance; it works for scooters; it is quick, secure, and easy to use; and no hardware is needed on wheelchairs for it to work in LATVs. Although also rated highly, the autodocking system raised concern by operators due to the requirement for wheelchair passengers to align properly and steer backward into the system. While operators prefer the RF-WP system best, wheelchair passengers responded most positively to the autodocking system. According to the wheelchair passengers surveyed, the RF-WP was favorable due to its perceived stability, ease of use, and security, and because the RF-WP system did not require special wheelchair hardware for it to work on board an LATV. However, about 75 percent of wheelchair passengers mentioned discomfort associated with the use of the RF-WP system, resulting in 30 percent disliking the RF-WP system and 55 percent finding the RF-WP least comfortable to ride in. The discomfort was not only due to riding rearward but also to its perceived contribution to rocking movement induced by vehicle braking and accelerating during rearward travel in the RF-WP system. To improve RF-WP systems, wheelchair passengers suggested a means for upper-body support, improved usability of the system to aid wheelchair passengers in navigating into the system, and an interface that informs wheelchair passengers on upcoming stops. Wheelchair passengers agreed with LATV operators that the autodocking system needs some form of confirmation that the wheelchair is properly aligned and secured in the system.

Operators and wheelchair passengers agreed regarding the four-point tiedown system. Both liked the four-point tiedown system least due to its lack of independence for wheelchair passengers, its use being time-consuming, its difficulty of use, and the perception of it being less safe and secure than the autodocking and RF-WP systems. Wheelchair passengers suggested redesigning the four-point tiedown system so that wheelchair users can use the system without operator assistance. They also suggested adding a handhold to the securement station and recommended a better upper-torso restraint to provide more stability.

Public transportation has been attractive to passengers because of its accessible, public nature. Low-floor buses in combination with automated ramps have made a difference in how the increasing number of wheelchair passengers access LATVs. However, current wheelchair securement systems remain designed to require operator assistance. This defeats the purpose of truly accessible transportation and results in misuse and disuse of tiedown systems (Buning et al. 2007; Foreman and Hardin 2001; Frost et al. 2009; Nelson/Nygaard Consulting Associates 2008). 
For LATVs to be fully accessible, wheelchair securement systems and stations need to be designed accessible to the fullest extent possible. This means that the majority of wheelchair and scooter passengers who are able to independently travel can enter the securement station and be independently capable of operating the securement system to secure their wheelchair or scooter. This study supports the need for improvement in securement systems to meet the needs of both LATV operators as well as wheelchair passengers. Future securement systems need to be designed for quick use, the option of forward-facing travel, secure fit, ability to provide feedback to operators and users on correct securement, and usability by the majority of wheelchair passengers. The results from this study will be used to develop novel wheelchair securement systems for use in LATVs.

\section{Acknowledgments}

Support for this study was provided by the Department of Education, National Institute on Disability and Rehabilitation Research and the Rehabilitation Engineering Research Center on Wheelchair Transportation Safety (Grant \# H133E060064). The opinions expressed herein are from the authors and do not necessarily represent those of the funding agency.

The authors express their thanks to Pittsburgh Port Authority Transit for securement system installation and providing a vehicle and drivers for testing purposes. The authors acknowledge BodyPoint, Q'Straint, Invacare, Amigo, Sunrise Medical, and Sure-Lok for their support with designing prototypes, manufacturing components, and donating wheelchairs, securement systems, and seat belts.

\section{References}

Abelson, J., B. Altom, and D. Cannon. 2008. Status report on the use of wheelchairs and other mobility devices on public and private transportation. San Francisco, California: Easter Seals Project ACTION.

ANSI/RESNA. 2001. ANSI/RESNA WC-19: Wheelchairs used as seats in motor vehicles. Arlington: American National Standards Institute (ANSI)/Rehabilitation Engineering Society of North America (RESNA).

Blower, D., L. Schneider, and J. Woodrooffe. 2005. Characterization of transit-bus accidents resulting in passenger injuries for use in developing alternative meth- 
ods for transporting wheelchair-seated travelers. International Truck \& Bus Safety \& Security Symposium, November 14-16, 2005, Itasca, IL.

Buning, M. E., C. A. Getchell, G. E. Bertocci, and S. G. Fitzgerald. 2007. Riding a bus while seated in a wheelchair: A pilot study of attitudes and behavior regarding safety practices. Assistive Technology 19(4): 166-179.

Foreman, C., and J. Hardin. 2001. The challenges of wheelchair securement: Searching for solutions. Tampa: Center for Urban Transportation Research, National Center for Transit Research, University of South Florida.

Frost, K. L., and G. E. Bertocci. 2009. Retrospective review of adverse incidents involving passengers seated in wheeled mobility devices while traveling in large accessible transit vehicles. Medical Engineering and Physics 32(3): 230-236.

Frost, K. L., and G. Bertocci. 2010. Ingress/egress incidents involving wheelchair users in a fixed-route public transit environment. Public Transportation 13(3): 41-62.

Hardin, J. A., C. C. Foreman, and L. Callejas. 2002. Synthesis of securement device options and strategies. Tampa: National Center for Transit Research (NCTR).

Hobson, D. A., and L. van Roosmalen. 2007. Towards the next generation of wheelchair securement. Development of a demonstration UDIG-compatible wheelchair docking device. Assistive Technology 19(4): 210-222.

Hunter-Zaworski, Kate. 2004. An NCAT progress report: Rear facing securement for BRT-A Transit IDEA Project (July 2004). Oregon State University.

International Standards Organization (ISO). 2001. ISO7176, Part 19: Technical systems and aids for disabled or handicapped persons-wheelchairs. Wheeled mobility devices for use in motor vehicles. Geneva, Switzerland: International Standards Organization.

ISO. 2001. ISO/DIS 10542-1: Wheelchair tiedowns and occupant restraint systemsPart 1: Requirements and test methods. Geneva, Switzerland: International Standards Organization.

ISO. 2005. 10542-3: Technical systems and aids for disabled or handicapped persons-Wheelchair tiedown and occupant-restraint systems-Part 3: Docking type tiedown systems. Geneva, Switzerland: International Standards Organization. 
ISO. 2010. ISO/DIS 10865 Part 1: Assistive products for persons with disabilityWheelchair containment and occupant retention systems for motor vehicles designed for use by both sitting and standing passengers-Part 1: Systems for rearward facing wheelchair-seated passengers. Geneva, Switzerland: International Standards Organization.

Nelson/Nygaard Consulting Associates. 2008. Status report on the use of wheelchairs and other mobility devices on public and private transportation. Washington, D.C: Easter Seals Project ACTION.

Project Action. 2008. Status report on the use of wheelchairs and other mobility devices on public and private transportation. San Francisco, CA.

Shaw, G. 2008. Investigation of large transit vehicle accidents and establishing appropriate protection for wheelchair riders. Journal of Rehabilitation Research and Development 45(1): 85-108.

Society of Automotive Engineers (SAE). 1999. SAE J2249: Wheelchair tiedowns and occupant restraint systems: Surface vehicle recommended practice. Warrendale, PA: SAE.

Songer, T., S. G. Fitzgerald, and K. Rotko. 2004. The injury risk to wheelchair occupants using motor vehicle transportation. 48th Annual Proceedings of the Association for the Advancement of Automotive Medicine.

Turkovich, M. J., L. van Roosmalen, Hobson D. A., and E. A. Porach. 2011. The effect of city bus maneuvers on wheelchair movement. Journal of Public Transportation 14(3): 147-169.

Turkovich, M, J., L. van Roosmalen, D. A. Hobson, and E. A. Porach. 2009. Assessment of wheelchair securement systems in a large accessible transit vehicle. Rehabilitation Engineering Society of North America, June, New Orleans.

United Kingdom Department for Transport. 2011. Carriage of mobility scooters on public transport-Feasibility study 2006 [cited March 2 2011]. Available from http://www.dft.gov.uk/transportforyou/access/tipws/cmspt/carriageofmobilityscooterson6163.

U. S. Department of Transportation (DOT). 2010. Part 37-Transportation services for individuals with disabilities. 49 CFR 37: Federal Transit Administration.

U. S. DOT. 2010. Part 38-Accessibility specifications for transportation vehicles. 49 CFR 38: Federal Transit Administration. 
van Roosmalen, L., P. Karg, D. A. Hobson, M. Turkovich, and E. Porach. 2011. User evaluation of wheelchair securement systems in large transit vehicles. Journal of Rehabilitation Research and Development 48(7): 823-838.

\section{About the Authors}

LINDA VAN Roosmalen, Ph.D. (Linda@LINC-Design.com) is Principal at LINC Design LLC, Verona, PA (www.LINC-Design.com) and lead investigator on the RERC on Wheelchair Transportation Safety.

Douglas A. Hobson, Ph.D. (dhobson1@mac.com) is Emeritus Associate Professor at the University of Pittsburgh in the Department of Rehabilitation Science and Technology.

PATRICIA E. KARG, M.S. (tkarg@pitt.edu) is Assistant Professor at the University of Pittsburgh in the Department of Rehabilitation Science and Technology and CoDirector of the RERC on Wheelchair Transportation Safety.

Emily DeLeo, B.S. (emilydeleo@gmail.com) is a graduate student at the School of Physical Therapy, Duke University, Durham, NC.

ERIK PORACH, B.S. (eap26@pitt.edu) is a Research Specialist at the University of Pittsburgh Department of Rehabilitation Science and Technology. He supports projects in the RERC on Telerehabilitation, Spinal Cord Injury, and on Wheelchair Transportation Safety. 